\title{
Resenha do Livro A Direita Intransigente Chega aos Trópicos: sobre Leo Strauss e Eric Voegelin e a Busca de uma Ordem Pós-Liberal
}

Ronaldo de Souza

\author{
Ronaldo de Souza \\ Doutor em ciência política pelo Departamento de Ciência Política da \\ USP e Mestre em ciências sociais (área de concentração-Política) pelo \\ Programa de Pós-Graduação em Ciências Sociais da PUC-SP. \\ ORCID: http://orcid.org/0000-0002-5602-7064
}

Quando formulou o termo direita intransigente o lendário editor da New Left Review, o historiador e ensaísta inglês Perry Anderson, argumentava que se quiséssemos compreender parte da política nas chancelarias no contexto europeu e norte-americano no fim do século XX deveríamos voltar nossas atenções para a obra de quatro figuras intelectuais decisivas no debate de ideias deste período. Como o próprio Anderson afirmara (Boitempo, 2002), vindos de disciplinas diferentes (história, filosofia, direito e economia), Michael Oakeshott, Leo Strauss, Carl Schmitt e Friedrich Von Hayek dedicaram um espaço fundamental em seus pensamentos e reflexões sobre os problemas políticos enfrentados pelas modernas sociedades ocidentais - para eles em processo de declínio. Transformaramse ao longo do tempo em eruditos teóricos da política. Se Carl Schmitt e Friedrich Von Hayek já são pensadores conhecidos em profundidade em nosso debate acadêmico e público; Leo Strauss, Oakeshott e Eric

Voegelin (que não é analisado por Anderson na ocasião em que formulou o termo direita intransigente, mas bem poderia sê-lo dada sua localização nas circunstâncias tratadas pelo historiador), ainda que reconhecidos como de importância imprescindível para a conformação das ideias de direita não mereceram até o momento atenção mais profunda por parte do mundo campi brasileiro. Uma hipótese para isto pode ser formulada a partir da consideração do pesquisador e professor de ciência política da USP Bernardo Ricupero: das ambiguidades e mesmo dificuldades de lidar com nosso passado (2010, p. 80), ou seja, de se ser de direita ou conservador no âmbito de uma sociedade marcada por um passado não glorioso de escravidão e da presença de uma elite patriarcal violenta e cruel que raramente deixou de dominar os negócios estatais. Haveria que se ter a coragem de sustentar convicções de um momento derradeiro e de concepções teóricas que, eventualmente, formariam um mapa cognitivo de interpretação da sociedade em geral e da nossa em particular.

Entretanto, com as recentes traduções pela $E$ Realizações, diga-se desde já que é de se elogiar a iniciativa desta casa editorial, de obras comentando as ideias de Leo Strauss e Eric Voegelin, além dos próprios escritos dos dois teóricos conservadoresi, a direita intelectual vem ocupando - ou reocupando - espaço cultural no nosso debate intelectual e público. Se isto será proveitoso para uma discussão plural, reflexiva e eticamente orientada sobre o que de fato esses autores diziam e dizem, escreviam e escrevem - somente o tempo dirá. Dentre as obras traduzidas e editadas pela ÉRealizações uma merece a atenção especial de nossas ciências sociais, a saber: Revolta contra a modernidade: Leo Strauss, Eric Voegelin e a busca de uma ordem pós-liberal. Escrita por Ted Mcallister, professor titular 
RESENHA DO LIVRO A DIREITA

INTRANSIGENTE CHEGA AOS

REVISTA ESTUDOS POLÍTICOS Vol. 10 | N.1 ISSN 2177-2851

TRÓPICOS: SOBRE LEO STRAUSS E

ERIC VOEGELIN E A BUSCA DE UMA

ORDEM PÓS-LIBERAL

Ronaldo de Souza

de políticas públicas na Universidade Pepperdine nos Estados Unidos, o livro é resultado de um projeto de dissertação sobre o "cerne intelectual do movimento conservador" (Mcallister, 2017, p. 10), mas que no transcorrer da execução resultou por privilegiar dois eminentes intelectuais daquele movimento. Mcallister concentrou sua investigação em Leo Strauss e Eric Voegelin - e à "crítica do mundo moderno, que foi articulada [pelos] dois imigrantes europeus" (Ibidem, p. 11). Com efeito, este é o argumento decisivo do livro Revolta contra a modernidade: Leo Strauss, Eric Voegelin e a busca de uma ordem pós-liberal (doravante $R C M)$; que pode ser expresso de outra maneira: a obra de Mcallister procura compreender o porquê e como dois dos principais teóricos políticos do século XX escreveram suas respectivas obras em clara e intransigente oposição às formas existências da era moderna. Nos oito capítulos que compõem o livro Mcallister esforça-se para sustentar esta argumentação. Vejamos alguns pontos importantes de RCM. E ao menos três gostaria de propor à atenção do leitor no momento de se debruçar no estudo de texto tão valioso para nosso debate intelectual, acadêmico e, sobretudo, crítico-progressista.

Os três pontos são: 1) a definição de conservadorismo que Ted Mcallister apresenta baseando-se na teoria política de Strauss e Voegelin, por outras palavras, o sentido do pensamento de direitai conformado no contexto das obras dos dois emigrados ${ }^{\text {iii }}$ germânicos escrevendo em circunstâncias norte-americanas de meados do século passado; 2) a interpretação da modernidade de Strauss e Voegelin que Mcallister observa como que ensejando a deificação de homens e mulheres; e 3) a resposta que um e outro propõem diante da ordem moderna e liberal em processo constante de declínio político, moral e cultural. (Obviamente que o livro de Mcallister tem outros pontos de argumentação e que são importantes para o entendimento do conservadorismo no século XX: pode-se citar neste aspecto a articulação do conservadorismo dos dois emigrados com o ambiente político norteamericano tratado no capítulo 2 A américa liberal e seus focos de descontentamento.) Passemos aos três pontos destacados pela nossa resenha de $R C M$.

Uma definição preliminar do pensamento conservador, ou das ideias de direita, diz que é a busca por manter os costumes constituídos no decurso histórico - decurso histórico esse na qual as convenções particulares da experiência social se exprimem com primazia sua preocupação fundamental. A paixão por formalizações normativas e racionalmente construídas acerca da vida correta a ser apreciada e vivida pelos indivíduos torna os conservadores: rigorosamente cautelosos e prudentes. Edmund Burke foi o precursor dessa disposição vigilante aos modos de prescrição valorativa que se opunha à organização prática das sociedades humanas. Essa definição é lapidar para caracterizarmos o pensamento de direita de matriz inglesa; mas é insuficiente para apreendermos o significado do estilo de conservadorismo constitutivo da filosofia política de Leo Strauss e Eric Voegelin. RCMé valoroso como iniciação a estes dois autores do panteão conservador por dispor ao leitor o núcleo específico das ideias de direita que os corpus teóricos straussiano e voegeliniano dão sustentação. Assim, diferente da escola burkeana, Ted Mcallister deixa claro que Leo Strauss $^{\text {iv }}$ e Eric Voegelin defendem em suas obras, e de maneira intransigente pode-se dizer, "uma ordem que transcende" (Mcallister, 2017, p. 30) às ações práticas e convencionais dos homens. A implicação disto: é a recusa pelo conservadorismo dos dois emigrados de toda forma de "conhecimento objetivo por métodos das ciências físicas" (Ibidem, pp. 30 e 31) forjado na modernidade para o controle e transformação constante, ininterrupto, da natureza. A interpretação de Mcallister segue abordando as consequências teóricas e políticas da noção de ordem transcendente pela qual argumentam Strauss e Voegelin. Nas páginas 31 , 32 e 38 é possível averiguarmos com precisão tais desdobramentos. O primeiro deles refere-se a problemas epistemológicos; a preocupação dos dois teóricos, de acordo 
RESENHA DO LIVRO A DIREITA

INTRANSIGENTE CHEGA AOS

REVISTA ESTUDOS POLÍTICOS Vol. 10 | N.1 ISSN 2177-2851

TRÓPICOS: SOBRE LEO STRAUSS E

ERIC VOEGELIN E A BUSCA DE UMA

ORDEM PÓS-LIBERAL

Ronaldo de Souza

com $R C M$, com o desenvolvimento que na era moderna tem o conhecimento enquanto tal a que referimos há pouco, e o que se pode conhecer no âmbito da existência e suas questões fundamentais. Neste ponto específico configura-se a concepção na qual o conservadorismo peculiar de Leo Strauss e Eric Voegelin (distinto do de Edmund Burke e dos ingleses - anglosaxão, por assim dizer) como modo de conhecimento pelo que se busca incessante e, apaixonadamente, pelas respostas às "questões perenes" (Ibidem, p. 31).

Com efeito, Mcallister oferece ao leitor um dos eixos constitutivos do pensamento de direita de Strauss e Voegelin, a compreensão fundamental de que a filosofia e a filosofia política devem procurar conhecer o significado da "ordem normativa [...] constante [...]" (Ibidem, p. 32) e, dessa maneira, procurar impor "uma ordem política" (Ibidem) simetricamente constante - perene. Este segundo desdobramento organiza os pressupostos da interpretação e reposta (voltaremos a esta mais à frente) de nossos dois emigrados, qual seja; o entendimento de que uma vez que a modernidade tem se caracterizado por um impulso social "cambiante" (Ibidem), de transformação material imanente, a única possibilidade para as sociedades europeia e americana deveria ser a luta intransigente por:

\begin{abstract}
Uma ordem normativa [...] que mantêm tradições humanas em alta conta. [E mais] uma ordem [normativa] impositiva, que transcenda o controle humano, ao mesmo tempo que enfatizam que os limites do conhecimento humano exigem a dependência de métodos adaptáveis a um mundo mutável [Grifo meu] (Mcallister, 2017, pp. 32, 33).
\end{abstract}

A interpretação de Mcallister aqui é primorosa como se pode observar na citação para o leitor de ciências humanas e ciência política em particular interessado em estudar: 0 pensamento intransigente de parte da direita no século XX e XXI. Resenhemos um pouco mais dele então. Se modernidade significa o impulso disruptivo para a transformação da natureza - da política, do social, da moral, da estética é o que quer dizer - de modo a possibilitar aos homens e mulheres uma vida mais livre, igualitária e justa, então o que se deverá enfatizar para Strauss e Voegelin é uma teorização que demonstrasse "que o ser humano pertence a uma ordem não criada por ele" (Ibidem, p. 38). Ora, do que se necessitava inadiavelmente nos diz Mcallister, nos termos dos dois emigrados germânicos era a recuperação da força da "ordem normativa" (Ibidem), que se colocaria de maneira inflexível - diante dos "projetos modernos de [existência] destinados a criar um desordem social e existencial sem precedentes" (Ibidem). E que seria devastadora.

Chegou-se a esta circunstância de desordem para Leo Strauss e Eric Voegelin porque os homens e mulheres passaram a autocompreender-se como deuses que poderiam transformar todos os modos de existência natural impositivos. RCM neste aspecto faz dois movimentos teóricos explicativos em consonância com as respectivas obras dos nossos emigrados. Assim, a autocompreensão deificada pelo que se vislumbra a modificação da ordem normativa (natural) tem no caso de Strauss a figura de Maquiavel representando o "comportamento humano [livre] dos ditames coercitivos de um deus" (Ibidem, p. 160). Os homens tinham a capacidade decisiva para serem os "fundadores" (Ibidem, p. 161) sociais na qual a inauguração de novas ordens e novos modos de organização do "bem comum" (Ibidem, p. 162) dependeria exclusivamente do "conhecimento" (Ibidem), e, sobretudo, do "desejo de gloria imortal" (Ibidem) dos indivíduos. De modo que a modernidade maquiaveliana está destinada a impulsionar "os homens a sair[em] de um universo de necessidade para um reino de quase divina liberdade, com fins postulados por seus desejos e sua elaborada ciência empregada na descoberta ou criação de meios apropriados a esses e 
Ronaldo de Souza

desejos" (Ibidem, p. 164). Com efeito; a deificação da existência dos homens e mulheres que a ciência política de Maquiavel legou é algo "chocante [e] problemático" (Ibidem, p. 165) para Strauss - nos diz Ted Mcallister. Ele, Maquiavel, destruiu, toda a "tradição [que] postulava fins definidos [pela] (natureza) para os homens" (Mcallister, 2017, p. 163) como pressuposto na construção da boa "ordem política" (Ibidem). A compreensão "filosófica clássica que se origin[ou] com Platão" (Ibidem) era o objetivo crítico da modernidade e do florentino.

O outro movimento empreendido por $R C M$ teorizando acerca da autocompreensão deificada constitutiva da era moderna tem na nova ciência política de Eric Voegelin seu núcleo de interpretação. O conceito voegeliniano de revolta egofânica distinguirá o "homem moderno paradigmático" (Ibidem, p. 171) consoante às questões mais angustiantes que 0 pensamento de direita terá de tratar - sobretudo no século XX. Se no mundo grego antigo o equilíbrio da vida foi possibilitado pela aceitação daquilo que Platão nomeou como a "intermedialidade da existência humana" (Ibidem, p. 175), ou seja, a "tensão inerente" (Ibidem) que enuncia a submissão natural dos homens e mulheres a viverem entre o "polo das experiências mundanas [...] [e o] polo das experiências divinas ou numinosas" (Ibidem, p. 178); na era egofânica, a modernidade que Voegelin definia, como nos mostra Mcallister, também como um momento de "doença espiritual [...] uma desordem" (Ibidem, p. 173) da alma, se autocompreendia enquanto momento histórico e cultural em que os indivíduos "devem criar uma ordem" (Ibidem, p. 174) espelhando sua imaginação (racional) e construtiva. A figura do intelectual, Ted Mcallister nos chama a atenção, merecerá de Voegelin e sua nova ciência política a culpa pela deificação da humanidade. Assim, "o equivalente moderno do sofista é o intelectual, rotulo de opróbrio para os conservadores [...] Voegelin demonstrou o raciocínio deformado [do] intelectual (Ibidem), na medida em que seu "estilo de pensar [...] encorajava a irresponsabilidade [ou] a liberdade de pensamento" (Ibidem, p. 190). Voltaire e os Philosophes illuministes, Marx e os partidos comunistas lançaram a humanidade deificada na busca livre pelo "paraíso" (Ibidem, p. 192) na terra, que no caso específico dos últimos significava a "abolição da propriedade privada [...] o objetivo final da revolução" (Ibidem, p. 194). Voegelin foi claro afirma Mcallister: para o autor de Ordem e história o homem como deus e seu desejo imanente de "tornar realidade o paraíso final prometido por alguma deformação ideológica da realidade" (Mcallister, 2017, p. 200) tem sido o responsável pelas catástrofes do século XX. Qual a reposta apresentada por Leo Strauss e Eric Voegelin a este estado de coisas?

Há uma diferença sensível no andamento da resposta de Leo Strauss e Eric Voegelin à crise da era moderna. No capítulo 6, 0 filósofo, e 7, 0 místico, Ted Mcallister examina a proposta de resolução dos dois emigrados para os problemas por eles apresentados. Diz ele:

As afinidades entre Voegelin e Strauss são mais pronunciadas no diagnostico que fazem da crise moderna. Com poucas variações, ambos reúnem os principais suspeitos e os acusam dos mesmos crimes. $E$, apesar das diferenças de ênfase, os diagnósticos de Strauss e Voegelin são muito parecidos. A resposta de ambos à crise - suas filosofias mais positivas [no entanto] - apontam direções diferentes, mas jamais opostas (Mcallister, 2017, p. 267).

Deste modo, enquanto as resoluções apresentadas por um e outro nunca são essencialmente antagônicas, as modalidades de argumentação e a estratégia teórica de 
RESENHA DO LIVRO A DIREITA

INTRANSIGENTE CHEGA AOS

REVISTA ESTUDOS POLÍTICOS Vol. 10 | N.1 ISSN 2177-2851

TRÓPICOS: SOBRE LEO STRAUSS E

ERIC VOEGELIN E A BUSCA DE UMA

ORDEM PÓS-LIBERAL

Ronaldo de Souza

Strauss e Voegelin são distintas. O distinguished professor de ciência política na

Universidade de Chicago estilizou a filosofia política antiga (Sócrates, Platão, Aristóteles) e o titular da cátedra Max Weber de ciência política na Universidade de Munique e também pesquisador no Instituto Hoover ${ }^{\prime}$ da Universidade de Stanford historicizou a experiência místico-filosófica. Estas considerações são o ponto alto de RCM. Pois elas permitem ao leitor iniciante entender com certa profundidade que o pensamento político de direita no século XX é intransigente. Isto na medida em que a reposta de Leo Strauss para os problemas oriundos da modernidade foi o retorno "à caverna natural" (Ibidem, p. 298), em que a possibilidade de "transcendência do histórico ou parcial" (Ibidem, p. 321) ocorreria. Em outras palavras, a luta contra a era moderna em termos straussianos, argumenta Mcallister, tem o intuito de opor-se fortemente aos impulsos sociais, históricos e morais para "reconstruir o mundo [com a] esperança de transformação" (Ibidem, p. 306) - e o meio para isto resultava em reler as lições da filosofia política antiga que impunha com rigor, na interpretação de Strauss, a necessidade de "obediências às leis" (Ibidem, p. 328) como condição de "todo regime político [baseado] em uma vida natural" (Ibidem)

hierarquicamente estabelecida. Enquanto que a reposta e enfretamento de Eric Voegelin voltavam-se para uma crítica erudita aos "sistemas da modernidade (por exemplo, os de Hegel e Marx) como produtos de corações libidinosos' (Ibidem, p. 340), pelo que a ciência política voegeliniana, assevera Mcallister, orientava sua ação, rigorosa e inapelavelmente, pela "busca [e a reconstrução] da ordem" (Mcallister, 2017, p. 348), vale dizer, Voegelin projetou sua obra como a "narrativa maior, que seria estruturad[a] [do] começo [ao] fim [...] da história da ordem em favor da consciência histórica e a perene luta humana pela ordem" (Ibidem, p. 378). Os decisionismos metafísicos ${ }^{\text {vi }}$ de Leo Strauss e Eric Voegelin, a imposição normativa da transcendência natural e da ordem política mística, foram as lições que o pensamento de direita proferiu para os problemas que conformam o espírito moderno que foi bem sintetizado por Habermas em $O$ discurso filosófico da modernidade: "o mundo novo, o mundo moderno, se distingue do velho pelo fato de que se abre ao futuro [...] [isto] faz parte da consciência histórica da modernidade [...] a cesura [...] a ruptura com 0 passado como [...] renovação continua" (Habermas, 2002, p. 11).

Assim, o livro de Ted Mcallister, sobre a filosofia política de Leo Strauss e Eric Voegelin é um trabalho esmerado para os que objetivam compreender (e criticar como quem escreve esta resenha) com certa profundidade as ideias conservadoras, de direita, sobretudo no atual contexto do debate público (intelectual, cultural e político) brasileiro e quiçá mundial. Se permanece alguma dúvida ou suspeita do valor de Revolta contra modernidade: Leo Strauss, Eric Voegelin e a busca de uma ordem pós-liberal, vejamos então:

Fundamental ao pensamento conservador [de direita] é uma crença em uma estrutura normativa que transcenda a existência puramente humana. Conservadores apelam a um critério de autoridade que, mesmo não tendo sido criado pelos homens, os responsabiliza. O problema adquire muitas formas. Da tradução da lei natural, e com ela a "razão correta", a um apelo à revelação ou a conceitos mais claramente platônicos de essências ou formas, todo co ${ }^{1}$ nservador depende de um padrão transhumano que torne razoáveis apelos à verdade, à justiça e à beleza. Por necessidade, conservadores devem amparar suas crenças sociais em uma filosofia idealista, talvez seja aí, mais do 

ORDEM PÓS-LIBERAL

Ronaldo de Souza

que em qualquer outro lugar, que princípios conservadores soem absurdos para os ouvidos modernos (Mcallister, 2017, p. 393).

Aos pesquisadores e intelectuais conservadores na universidade e na imprensa importa sedimentar suas ideias e difundir a obra que resenhamos; aos pesquisadores e intelectuais em teoria política e social crítica, no âmbito de nossas ciências humanas e sociais o decisivo será: estudar, compreender, emitir juízos interpretativos e criticar a ideias de Strauss e Voegelin que Ted Mcallister sintetiza.

(Recebido para publicação em fevereiro de 2019)

(Reapresentado em maio de 2019)

(Aprovado para publicação em maio de 2019)

\section{Cite esta resenha}

SOUZA, Ronaldo, 2019. Resenha do Livro A Direita Intransigente Chega aos Trópicos: sobre Leo Strauss e Eric Voegelin e a Busca de uma Ordem Pós-Liberal. Revista Estudos Políticos: a publicação semestral do Laboratório de Estudos Hum(e)anos (UFF). Rio de Janeiro, Vol.10 |N.1, pp.109-117, maio de 2019.

\section{Notas}

1. Recentemente, mais precisamente no segundo semestre de 2018 a É Realizações traduziu e publicou o Política da Fé e Política do Ceticismo de Michael Oakeshott.

2. Como o leitor irá perceber ao longo do texto há uma variação terminológica, ora utilizo conservador ou conservadorismo ora utilizo pensamento e/ou ideias de direita. Os motivos para isto são dois: primeiro não sobrecarregar o texto com o termo direita, mais politizado e ideologizado (o que quer que isso signifique precisa e teoricamente; intuímos que seja não científico, mas aqui, de certo modo, respeitamos o vocabulário e as convenções de nosso tempo avessos a discussões ideológicas); segundo porque se utilizássemos somente 0 termo conservadorismo atenuaríamos o significado histórico e político mesmo dos textos de Leo Strauss e Eric Voegelin, que são o material teórico da obra de Ted Mcallister. Ademais conservadorismo tende a ideia de moderação, prudência, cuidado e um certo espírito despolitizado o que obviamente não é o caso em Strauss e Voegelin.

3. Leo Strauss e Eric Voegelin fizeram parte dos emigrados europeus, sobretudo os alemães, que 

ORDEM PÓS-LIBERAL

Ronaldo de Souza

foram fundamentais na constituição das humanidades em solo americano. Para nosso interesse imediato Strauss, Voegelin e também Hannah Arendt estabeleceram no âmbito dos departamentos de ciência política os pressupostos filosóficos e epistemológicos da área de teoria política tal como a conhecemos hoje. Índice disto é o fato de que as principais obras dos três; o Direito natural e história de Strauss, A nova ciência política de Voegelin e A condição humana de Arendt foram resultados das Lectures Charles Walgreen na Universidade de Chicago nos anos 1950. As conferências Charles Walgreen foram idealizadas para que eminentes teóricos europeus refletissem acerca dos problemas existências e políticos após duas grandes guerras mundiais. Ver sobre isto Antonio Lastra y Bernal Torres Morales Introducción. Eric Voegelin-Leo Strauss: Fe y Filosofia/Correspondencia 1934-1964, ed. Minima Trotta (a É Realizações traduziu estas correspondências de Strauss e Voegelin a partir da edição inglesa; nesta há a introdução dos organizadores das cartas trocadas pelos dois emigrados, Peter Emberly e Barry Cooper); John Gunnell - Between Philosophy and Politics: the alienation of political theory, ed. The University of Massachusetts e

4. Elisabeth Glaser-Schmidt and Peter Graf Mewes (org.) Hannah Arendt and Leo Strauss: german emigrés and the American political thought after World War II, ed. Cambridge University Press.

5. Strauss divergiu do modo excessivamente histórico e convencionalista da abordagem de Edmundo Burke sobre a Revolução Francesa e os filósofos iluministas. Ver sobre isto: Leo Strauss - Direito natural e história. Martins Fontes, 2014.

6. Instituto Hoover desde a sua fundação em 1919 pelo republicano Herbert Hoover é um dos principais think tank conservador dos Estados Unidos.

7. Em Leo Strauss é mais perceptível os vestígios de decisionismos político e cultural do que em Eric Voegelin, que de fato há poucos, ou mesmo nenhum, elementos para tal consideração. Aqui estilizei o argumento sobre o teórico da metaxy ou in-between. No caso de Strauss especificamente, o impacto em seu pensamento da obra de Carl Schmitt, sobretudo, 0 conceito do político são reveladores há uma leitura mais atenta e circunspecta. Antes de chegar nos Estados Unidos vindo de um período como pesquisador na França e Inglaterra (aqui ele examinou 
Ronaldo de Souza

a obra de Thomas Hobbes), Strauss resenharia o mais importante texto do jurista do Reich e trocaria cartas com ele. Ver Heinrich Meier - Carl Schmitt, Leo Strauss y El concepto de lo político: sobre um diálogo entre ausentes, ed. Katz Editores.

\section{Bibliografia}

ANDERSON, Perry. A Direita Intransigente no Fim do Século. In: Afinidades Seletivas. São Paulo. Boitempo, 2002.

GLASER-SCHMIDT, Elisabeth and MEWES, Peter Graf. (org.) Hannah Arendt and Leo Strauss: german emigrés and the American political thought after World War II. Washington D. C. Cambridge University Press, 1997.

GUNNELL, John. Between Philosophy and Politics: the alienation of political theory. Amherst. The University of Massachusetts, 1986.

LASTRA, Antonio y MORALES, Bernal Torres. Introducción. Eric Voegelin-Leo Strauss: Fe y Filosofia/Correspondencia 1934-1964. Madrid. Minima Trotta, 2009.

MEIER, Heinrich. Carl Schmitt, Leo Strauss y El concepto de lo político: sobre um diálogo entre ausentes. Bueno Aires/Madrid. Katz Editores, 2008.

STRAUSS, Leo. Direito Natural e História. São Paulo. WMF Martins

Fontes, 
